\title{
ТЕХНИЧЕСКАЯ ПОДГОТОВЛЕННОСТЬ ГАНДБОЛИСТОВ В ПРОГРАММЕ СПЕЦИАЛЬНОЙ ОЛИМПИАДЫ
}

\section{TECHNICAL PERFORMANCE OF HANDBALL PLAYERS IN THE SPECIAL OLYMPIAD PROGRAM}

\section{Obivalina}

Summary: The object of the research is the requirements of competitive activity to the level of technical training of handball players for participation in the Special Olympics. The subject of the research is the technical preparation of Russian handball players for participation in the Special Olympics. The purpose of the study is to assess the general technical preparation of Russian handball players for participation in the Special Olympics, as well as to substantiate compliance with the requirements of the competition rules and the specifics of the games being played. To achieve the above goal, it is necessary to perform the following tasks: determination of the basic requirements and assessment of the competition in the technical training of athletes, as well as in different playing roles; identification of criteria for the effectiveness of throws in the basic directions of technical training of handball players for participation in the Special Olympics.

Keywords: handball player, handball, Special Olympics, competition, athletes.
Обивалина Мария Сергеевна

Стариий преподаватель, Российский государственный университет физической культуры, спорта, молодёжи и туризма m7m13@mail.ru

Аннотация: Объект исследования - требования соревновательной деятельности к уровню технической подготовки гандболистов для участия в Специальной Олимпиаде. Предмет исследования - техническая подготовка российских гандболистов к участию в Специальной Олимпиаде. Цель исследования заключается в оценке общей технической подготовки российских гандболистов к участию в Специальной Олимпиаде, а также в обосновании соответствия требованиям правил соревнований и особенностям проводимых игр. Для достижения вышеуказанной цели необходимо выполнить следующие задачи: определение основных требований и оценка соревнований при технической подготовке спортсменов, а также при различных игровых амплуа; выявление критериев эффективности бросков по базовым направлениям технической подготовки гандболистов к участию в Специальной Олимпиаде.

Ключевые слова: гандболист, гандбол, Специальный Олимпиада, соревнование, спортсмены.
$\Gamma$ андбол является одной из распространенных спортивных игр, которая зачастую применяется в соревновательной деятельности. В данном виде спорта принимают участие не только обычные люди, но и люди с ограниченными возможностями здоровья и различными особенностями развития (аутизм, синдром Дауна, ДЦП и др.). Стоит отметить, что особенности такого рода нельзя относить к заболеваниям, поскольку люди рождаются такими. Они также играют в гандбол, несмотря на сложность и особенности данной спортивной игры. Регулярные занятия физической активностью и различными видами спорта, в том числе и гандболом, способствуют улучшению психологического и эмоционального состояния людей. Участие в соревнованиях Специальной Олимпиады дает людям возможность ощутить себя принятыми в обществе, а также добиться успеха в спортивной сфере.

В настоящее время проблема участия людей с ограниченными возможностями здоровья в Специальной Олимпиаде является недостаточно рассматриваемой в отечественных СМИ. Тем не менее, первый опыт участия отечественных гандболистов в соревнованиях Специальной Олимпиады является весьма успешным, что под- тверждается полученными золотыми медалями 2014 года в Лос-Анджелесе. Между тем, обоснованной методики проведения занятий с данной группой спортсменов в нашей стране на текущий момент не существует.

Результаты проведенных исследований технической подготовки гандболистов разных игровых амплуа при помощи СГТ представлены в табл. 1 и на рис. 1, 2.

Полученные результаты показали, что точность бросков на первых ступенях подготовки, проходившей в июне, практически не отличалась. Средние показатели точности бросков не достигали 50\%. Так, среднее число попаданий с расстояния 9 м в контрольной группе II во время выполнения СТГ составило 4,075 на 10 бросков (коэффициент вариативности группы - 0, 408). Число попаданий в I группе в прошлом сезоне в среднем составляло 3,97 попаданий на 10 бросков (коэффициент вариативности группы - 0, 398).

Тем самым, значительные расхождения не наблюдаются.

После проведенного нами педагогического экспери- 
Показатели технических действий в нападении (точность бросков по воротам) гандболистов разных игровых амплуа в I -м и II-м сезонах

\begin{tabular}{|c|c|c|c|c|c|c|c|}
\hline \multirow{2}{*}{ Показатели } & \multirow{2}{*}{ Группы } & \multirow{2}{*}{ месяц } & \multicolumn{5}{|c|}{ Амплуа } \\
\cline { 4 - 9 } & & & Разыгр. n- 10 & Линейный n-10 & Полусред. n-10 & Край n-10 & Средн.3нач. \\
\hline \multirow{2}{*}{10 бросков } & II & июнь & 3,8 & 3,9 & 4,2 & 4,4 & 4,07 \\
\cline { 2 - 9 } & I & июнь & 2,5 & 5,2 & 3,4 & 4,8 & 3,97 \\
\hline \multirow{2}{*}{10 бросков } & II & август & 8,2 & 8,4 & 9,1 & 7,8 & 8,37 \\
\cline { 2 - 9 } & I & август & 2,7 & 5,4 & 3,7 & 5,1 & 4,22 \\
\hline
\end{tabular}

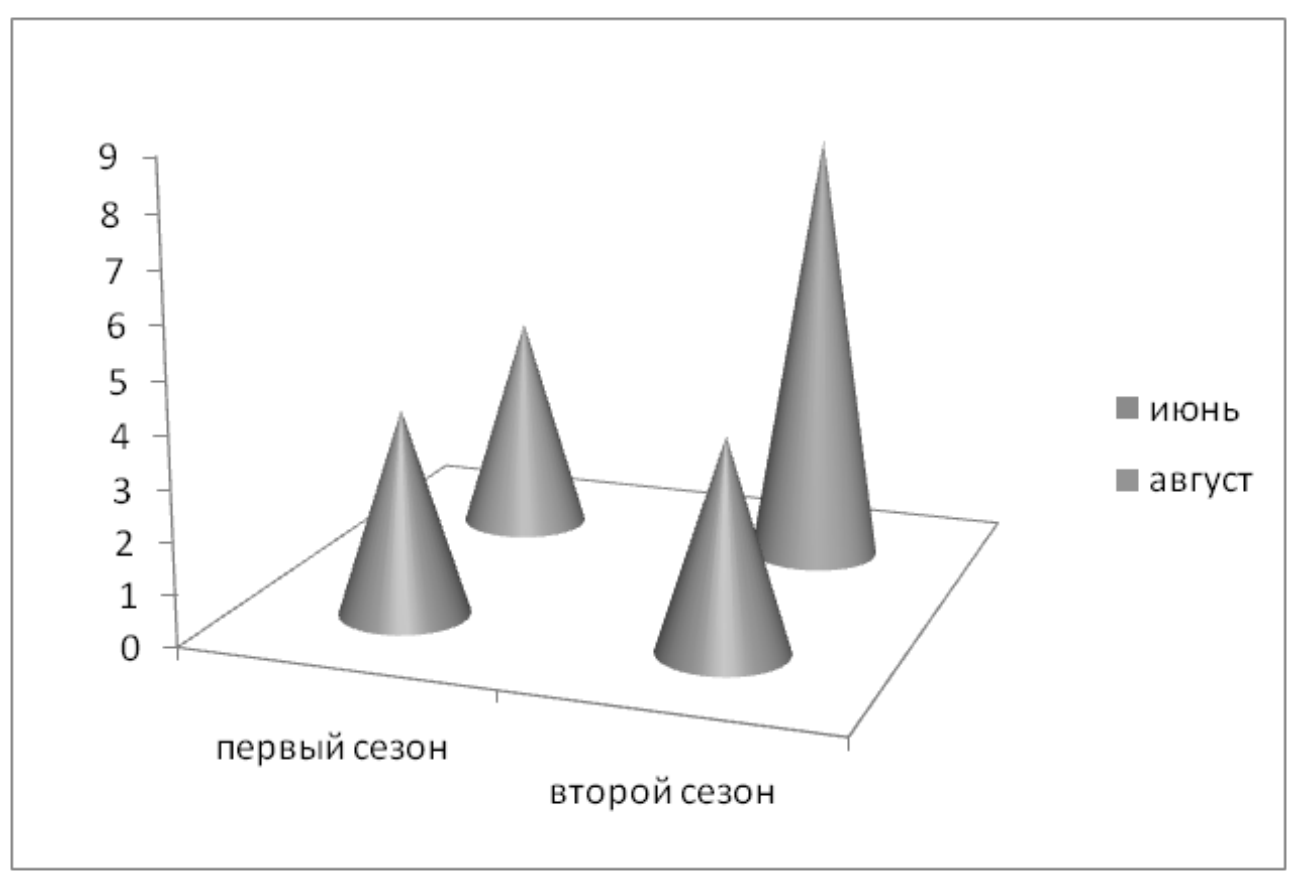

Рис. 1. Среднее значение точности бросков по воротам гандболистов в І-й и II-й исследуемых группах

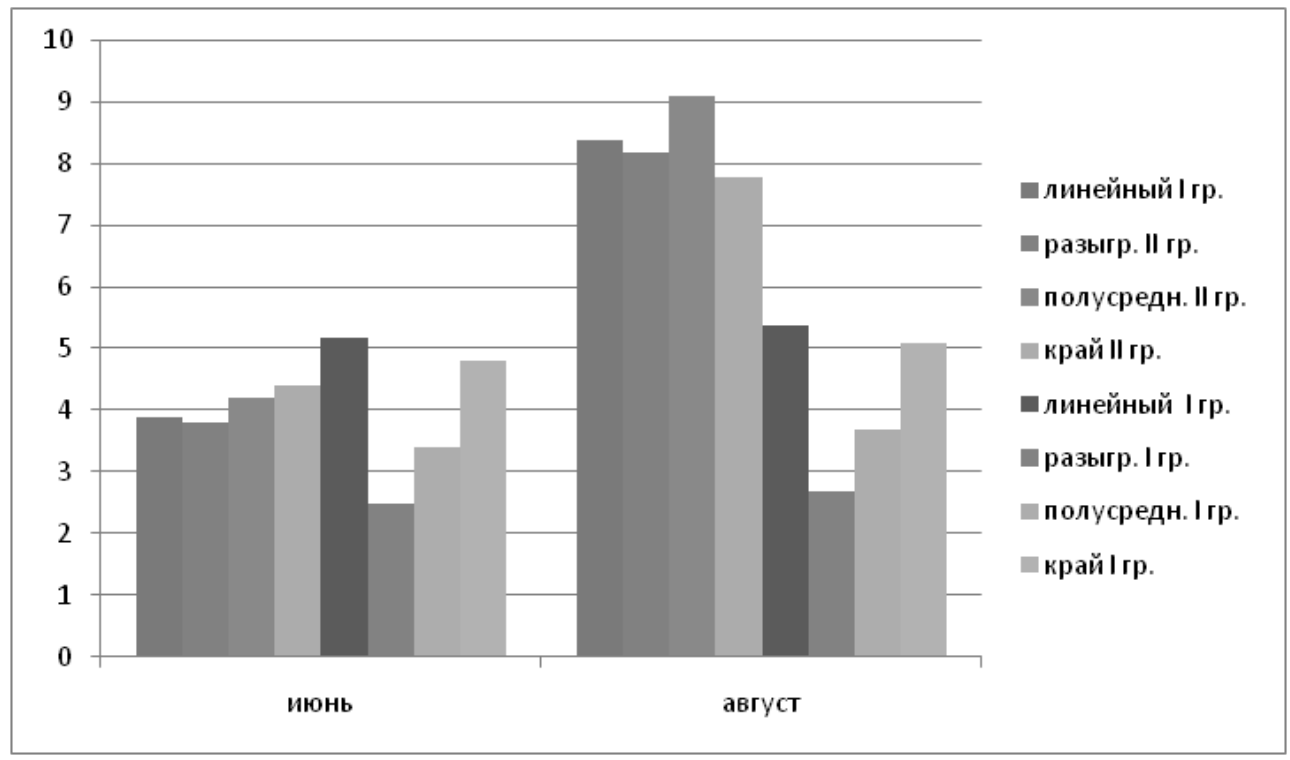

Рис. 2. Динамика показателей технической подготовленности (точность бросков по воротам) гандболистов разных игровых амплуа 
мента, который длился в течение года и заключался во введении в тренировочный процесс специальной программы, направленной на повышение точности бросков, у спортсменов II группы произошли значительные изменения. Так, существенным образом изменились показатели точности бросков в сравнении с прошлогодними результатами данной исследуемой группы, что показано в табл. 1.

В августе следующего года среднее число попаданий с расстояния 9 м составляло уже 8,37 на 10 бросков. Стоит отметить, что год назад среднее количество попаданий с расстояния 9 м в группе I достигло только 4,22 попаданий на 10 бросков (см. рис. 2). Коэффициент вариативности группы при этом составил 0,42.

Динамика показателей технической подготовки спортсменов разных игровых амплуа в I и II группах представлена на рис. 2. В июне лидерами по точности бросков во II группе были разыгрывающие (8,2 попадания), а в I группе - линейные игроки (5,2 попаданий). Уже в августе лидерами стали угловые игроки (9,1 попаданий) во II группе и те же линейные (5,4 попаданий) в I группе. Снижение точности бросков разыгрывающих игроков II группы в августе говорит о необходимости в изменении индивидуальной программы их физической подготовки. Повышение интенсивности нагрузок в матче выдвигает важные требования к уровню физической подготовки гандболистов. Это является особенно важным в конце матча, когда на общем фоне значительной усталости спортсменов, неточность броска может негативным образом повлиять на достижение победного результата, вследствие чего все командные усилия останутся напрасными. Итоговые показатели точности бросков свидетельствуют о положительных изменениях в показателях технической подготовки обеих исследуемых групп спортсменов и эффективности разработанной тренировочной программы, направленной на улучшение точности бросков, что в значительной степени воздействует на результативность соревнований. Тем самым, результаты комплексных исследований посредством использования специального гандбольного теста подтверждают эффективность и качество предлагаемой тренировочной программы, которая была разработана с целью существенного улучшения технической подготовки спортсменов для формирования наиболее высокой точности бросков.

\section{ВывоАы}

1. Исследование соревнований гандболистов дает возможность выделить основные факторы, которые в значительной степени воздействуют на результат матча, а также позволяет сформировать определенные модели игры для спортсменов разных амплуа. Кроме того, в результате исследо- ваний становится возможным выявление тенденций развития спортивной игры и её технических составляющих. Также при исследовании данной соревновательной деятельности удалось определить точные сведения о преимуществах и недостатках подготовленности каждого игрока команды и осуществить коррекцию тренировочного процесса при учёте анализа спортивной игры.

Обследование соревнований считается значимым элементом в комплексном педагогическом контроле. Для управления подготовкой гандболистов крайне важно иметь объективные сведения об уровне реализации их подготовки в условиях соревновательной деятельности. Как показала практика, процесс подготовки к игре следует выстраивать согласно запросам соревнований. В гандболе соревнование представляет собой один из методов интегральной подготовки, а средством данной подготовки выступает специально организованная и управляемая учебная игра.

Собственно исследования соревнований гандболистов ведутся в нескольких направлениях. Прежде всего, исследование осуществляется для получения информации для формирования модели соревнований с целью её моделирования в тренировочных условиях. Помимо этого, исследования необходимы для получения сведений о динамике показателей каких-либо отдельных спортсменов с целью контроля эффективности их подготовки. Стоит отметить, что незначительная разработка количественных характеристик становится тормозом общей оценки проводимых соревнований. Значительная трудность получения данной информации заключается непосредственно в том, что итоговый результат выступления команды достигается в разных соревнованиях с самыми разными соперниками.

2. Гандболисты из экспериментальной группы обладали более высоким уровнем развития технической подготовки, нежели их сверстники из контрольной группы. В свою очередь, в контрольной группе также наблюдались положительные результаты в показателях технической подготовки, но они не имели статистическую значимость в отличие от спортсменов экспериментальной группы.

3. На точность броска и передачи в гандболе воздействует способность спортсмена осуществлять воспроизведение ранее освоенных движений, а также навык правильного определения точного направления и расстояния до партнера по команде или до ворот. В тренировке используются самые разные техники и методы с изменением дистанции при передачах мяча. Наиболее эффективными такими методами являются следующие: 
«точечный», метод «контрастных заданий» и техника «сближаемых заданий».

Важно указать, что при выполнении «точечного» метода броски осуществляются с постоянного места, но при этом изменяются способы выполнения приема. Так, изменяются ограничения размеров ворот, высота передачи и т.д.

\section{Критерии эффективности бросков.}

Игрок должен:

1. выяснить, в какое время и каким именно способом бросать мяч, когда необходимо осуществить бросок, а когда стоит передать мяч партнеру, который находится в наиболее удобной позиции для броска. Кроме того, игроку необходимо овладеть базовыми способами бросков и развить все те, которые в наибольшей степени подходят лично для него;

2. иметь способность расслабляться при осуществлении броска, развивать это на всех тренировках;

3. иметь уверенность в собственных способностях. Необходимо воспитывать в себе ощущение способности осуществлять каждый бросок мяча. На тренировках стоит начинать выполнять броски с близкого расстояния и постепенно увеличивать дистанцию. Такая техника позволит усовершенствовать уверенность в своих бросках;

4. обладать равновесием и сохранять основную позицию. Несмотря на то, что каждый способ броска определяется своей позицией, спортсмены при любом броске должны находиться в равновесии, удерживать мяч двумя руками и сохранять основную позицию. Исключительно после этого гандболист может сделать бросок. При этом существует ряд исключений из данного правила, однако оно остается базовым при осуществлении бросков;

5. использовать различные способы разбега при выполнении бросков. При разбеге обычными шагами замах и метание должны проводиться при обязательной опоре на одну ногу. Для повышения точности и ускорения броска стоит применять так называемые встречные силы махов бросающей руки и разноименной ноги;

6. выполнять тренировки в таких условиях, которые наиболее приближены к соревновательным. При отработке бросков необходимо работать в так называемой ситуации «один против одного», с подключением нейтрального игрока, который будет подавать мяч;

7. после освоения конкретных методов бросков игрок должен учиться бросать мяч в ворота максимально быстро, при этом не просто бросать, а контролировать мяч и собственные движения в течение всего времени выполнения броска;

8. выявлять направление броска мяча. Данное направление имеет зависимость от выпуска мяча по прямой линии, а также от корпуса нападающего к воротам. Когда при броске одной рукой спортсмен непрерывно направляет мяч в одну сторону, он должен убедиться в том, придается ли мячу небольшое обратное вращение и плавным ли образом он уходит с кончиков пальцев. В том случае, если этого не происходит, тогда собственно техника броска мяча является неправильной.

\section{Общие ошибки при выполнении бросков:}

1. отсутствие умения сосредоточения внимания на цели в завершающей стадии броска мяча;

2. низкая эффективность применения встречных сил махов бросающей руки и разноименной ноги;

3. излишне сильное вращение мяча;

4. низкий уровень равновесия тела;

5. спешка при осуществлении броска мяча;

6. отсутствие применения различных финтов перед броском мяча, в особенности при значительно плотной опеке;

7. разведение локтей при осуществлении броска мяча;

8. неумение принять определенную позицию после броска мяча непосредственно для перехода в защиту.

Весь процесс технической подготовки спортсменов должен быть основан на формировании наиболее оптимальных условий, необходимых для развития и совершенствования точного броска мяча. Это обусловлено тем, что именно выполнение точного броска в существенной степени зависит от используемых методов и правильной техники. Собственно обучение начинается с полного овладения верного исходного положения для игры. Далее происходит изучение согласованности движений рук и ног. Особенно значимым фактором являются умения прицеливания, что необходимо развивать одновременно с изучением движений броска мяча. Кроме того, следует сразу обучить спортсменов навыку одновременного видения цели и мяча, осуществляемого при контроле собственных движений до момента их завершения. 


\section{ЛИТЕРАТУРА}

1. Елеусизова С.К. Наука и практика социализации лиц с ограниченными возможностями // Современная наука: актуальные проблемы и пути их решения. - 2015. - № 4 (17). С. 222-224.

2. О Национальной стратегии действий в интересах детей на 2012-2017 гг. Указ Президента РФ от 1 июня 2012 г., № 761 // Логопед. - 2012. - № 9. C. $96-110$.

3. 0 соблюдении прав детей-инвалидов в Российской Федерации: специальный доклад Уполномоченного по правам человека в РФ // 0фициальные документы в образовании. - 2006. - № 31 (243). - С. 27-53.

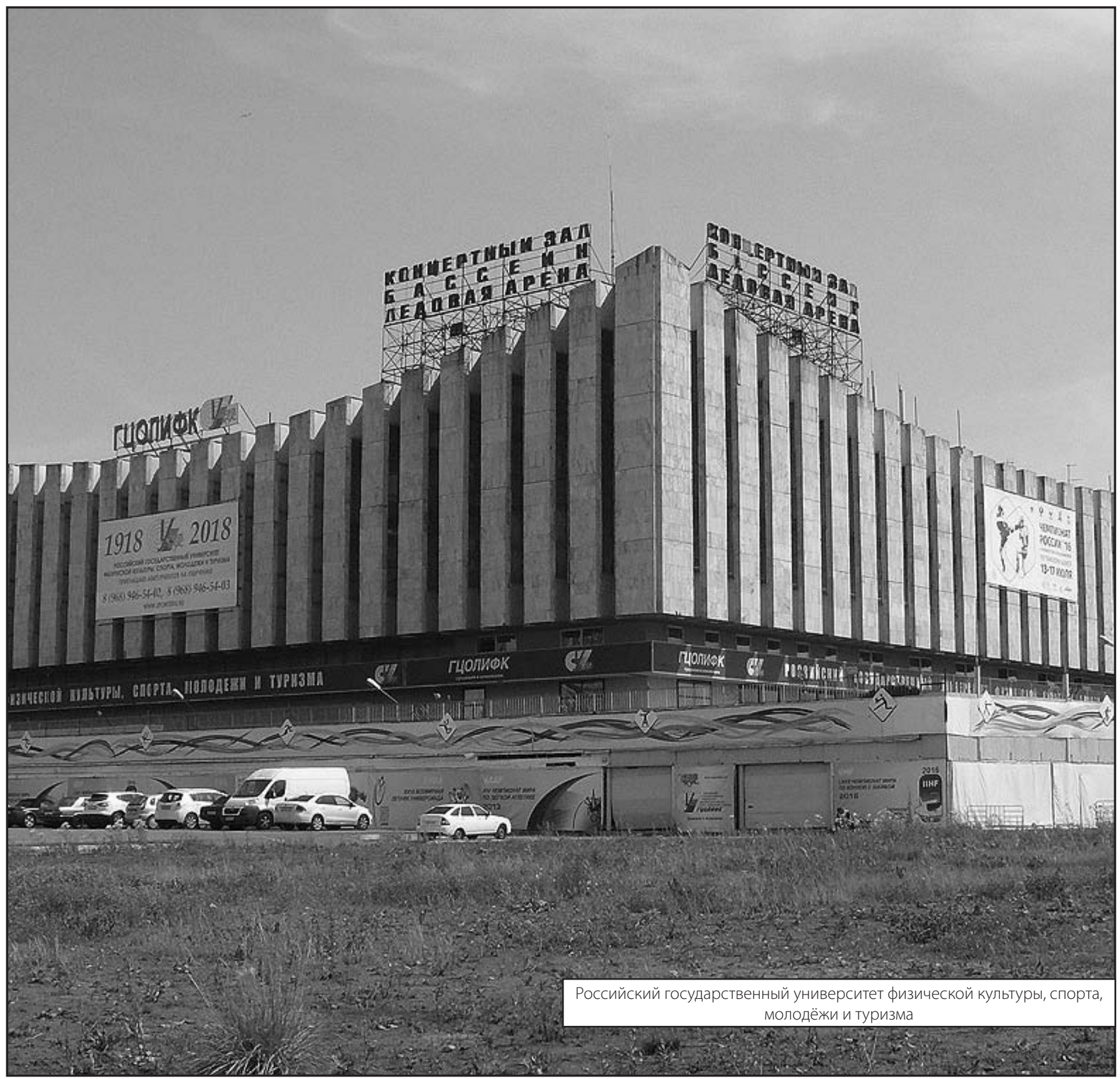

